\title{
VORWORT ZUR ERSTEN RUSSISCHEN AUFLAGE
}

Der vorliegende Band des „Lehrbuches für Theoretische Physik“ beschäftigt sich mit der Theorie elektromagnetischer Felder in Substanzen und mit der Theorie makroskopischer elektrischer und magnetischer Erscheinungen der Stoffe. Wie man aus dem Inhaltsverzeichnis entnehmen kann, gehört hierzu ein sehr weiter Bereich von Fragen.

Beim Schreiben dieses Buches hatten wir viele Schwierigkeiten zu überwinden, die mit der Notwendigkeit zusammenhingen, eine Auswahl aus dem vorliegenden riesigen Material zu treffen, und auch damit, daß die gewöhnliche Darstellung vieler hier berührter Fragen nicht den nötigen Grad physikalischer Klarheit besitzt und teilweise sogar falsch ist. Wir sind uns darüber klar, daß auch in der vorliegenden Darstellung noch viele Mängel enthalten sind, die wir in weiteren Auflagen des Werkes richtigzustellen beabsichtigen.

Wir danken Prof. W. L. Ginsburg, der das Buch im Manuskript las und eine Reihe nützlicher Bemerkungen machte. Unser Dank gilt auch I. J. DsJaIoschrnski und L. P. PitaJewski für ihre große Hilfe beim Lesen der Korrekturen.

Moskau, Oktober 1956

L. D. Landau, E. M. Lifschitz 
